\title{
What to do now? How women with breast cancer make fertility preservation decisions
}

\author{
Karrie Ann Snyder, ${ }^{1}$ Alexandra Lee Tate ${ }^{2}$
}

${ }^{1}$ Lecturer, Department of Sociology, Northwestern University, Evanston, IL, USA ${ }^{2}$ Graduate Student, Department of Sociology, University of California, Los Angeles, CA, USA

\section{Correspondence to} Dr Karrie Ann Snyder, Department of Sociology, Northwestern University, 1810 Chicago Avenue, Evanston, IL 60208, USA; karrie-snyder@northwestern.edu

Received 22 November 2011 Accepted 9 August 2012 Published Online First 25 January 2013
To cite: Snyder KA, Tate AL. J Fam Plann Reprod Health Care 2013;39:172-178.

\section{ABSTRACT}

Objectives There has been increased attention paid to cancer-related infertility and fertility preservation. However, how cancer patients decide whether or not to pursue fertility preservation has not been fully examined. Methods The data come from 34 interviews with women in the USA diagnosed with breast cancer prior to 40 years of age who contemplated fertility preservation prior to cancer treatment. Fully transcribed interviews were coded through a three-staged inductive process. Results Three sets of factors that shaped the decision-making process of the respondents regarding fertility preservation treatment options were identified: perceived benefits (e.g. ability to use 'younger' eggs in the future), inhibiting concerns (e.g. success rates) and influential relationships (e.g. physicians, parents and partners).

Conclusions Respondents saw their main fertility preservation decision as choosing whether or not to pursue egg/embryo banking. The decision-making process was complicated and included both health-related and personal considerations, with many respondents reporting a lack of support services for fertility issues. Findings suggest that greater attention needs to be placed on presenting patients with a wider range of options. Those who counsel patients regarding fertility preservation decisions should be aware of the influence of relationship dynamics, broader health care concerns, and fertility histories on these decisions.

\section{INTRODUCTION}

Fertility preservation has become an increasingly addressed issue within the cancer community, with greater attention being paid to the potential impact of cancer treatment, including radiation and chemotherapies, on future fertility

\section{KEY MESSAGE POINTS}

While fertility preservation has garnered greater attention, less is known about how cancer patients make fertility preservation decisions.

- Despite the range of choices for fertility preservation, respondents identified egg/embryo banking as their primary option.

- Many factors outside of cancer concerns inhibit and facilitate fertility preservation decisions including fertility history and family relationship dynamics.

potential as well as the options available to cancer patients to help safeguard their fertility prior to undergoing potentially damaging treatments. Research has shown that fertility issues can be a major source of distress for cancer survivors. ${ }^{1-5}$ Unfortunately, several studies have shown that cancer patients do not routinely discuss cancer-related infertility or what can be done to help minimise the effects of cancer treatment on fertility prior to beginning cancer treatment. ${ }^{4}{ }^{6-10}$ Moreover, those who do discuss the issue often feel their concerns were not adequately addressed. ${ }^{4}$ 6-9 11-13 While gaps in the exchange of fertility-related information between cancer patients and doctors have been well documented, how patients make the decision of whether or not to pursue fertility preservation has not been as thoroughly examined. Often discussions of fertility preservation only touch on decision-making by either considering a single case $^{14}$ or discussing the potential issues, ${ }^{5}$ including religious, legal 
Table 1 Fertility preservation options for those with breast cancer*

\begin{tabular}{|c|c|c|c|}
\hline $\begin{array}{l}\text { Embryo banking (i.e. embryo } \\
\text { freezing, 'emergency' IVF) }\end{array}$ & $\begin{array}{l}\text { Egg banking } \\
\text { (i.e. oocyte/egg freezing) }\end{array}$ & $\begin{array}{l}\text { Ovarian tissue } \\
\text { cryopreservation } \\
\text { (i.e. ovarian tissue banking) }\end{array}$ & $\begin{array}{l}\text { Other options available prior } \\
\text { to cancer treatment }^{\dagger}\end{array}$ \\
\hline $\begin{array}{l}\text { "Harvesting eggs, IVF and freezing of } \\
\text { embryos for later implantation." } \\
\text { - Requires hormonal stimulation to } \\
\text { mature and harvest eggs. } \\
\text { - Can delay treatment up to } 1 \text { month } \\
\text { or more. }{ }^{19} \\
\text { - Requires sperm for fertilisation. }{ }^{19}\end{array}$ & $\begin{array}{l}\text { "Harvesting and freezing of } \\
\text { unfertilised eggs." } 19 \\
\text { Requires hormonal stimulation to } \\
\text { mature and harvest eggs. } \\
\text { Can delay treatment up to } 1 \text { month } \\
\text { or more. }{ }^{19} \\
\text { Does not require sperm for } \\
\text { fertilisation. }{ }^{19} \\
\text { Still considered experimental. }{ }^{19} \\
\text { Success rates: } \\
\text { - Considerably lower than for embryo } \\
\text { freezing, but } 200+\text { live births have } \\
\text { been reported. }{ }^{19}\end{array}$ & $\begin{array}{l}\text { Still considered experimental. }{ }^{19} \\
\text { Two options: } \\
\text { (1) Follicles from stored tissue can } \\
\text { be matured in vitro in order to } \\
\text { facilitate fertilisation. }{ }^{20} \\
\text { Success rates: } \\
\text { No live births. Successful } \\
\text { animal model trials. }{ }^{20} \\
\text { (2) Ovarian tissue can be } \\
\text { transplanted back into patient } \\
\text { post-cancer. }{ }^{19} \\
\text { Success rates: } \\
\text { Case reports of eight live births } \\
\text { worldwide. }\end{array}$ & $\begin{array}{l}\text { (1) Choosing a chemotherapy } \\
\text { regimen or treatment with a } \\
\text { lowered fertility risk. } \\
\text { (2) Ovarian suppression to protect } \\
\text { ovaries during chemotherapy } \\
\text { using GnRH analogues. }{ }^{19} \\
\text { (3) Gonadal shielding and } \\
\text { transpositioning during } \\
\text { radiation. }{ }^{1920}\end{array}$ \\
\hline
\end{tabular}

${ }^{*}$ These options are not limited to only those with breast cancer, but represent the range of current options available to women with cancer more generally. However, other cancers may have different advisable options.

${ }^{\dagger}$ Also, there are post-cancer options available such as adoption and surrogacy with donor eggs that physicians can also discuss with patients. ${ }^{19} 20$

GnRH, gonadotropin-releasing hormone; IVF, in vitro fertilisation.

and ethical concerns ${ }^{15} 16$ that patients may encounter. Only a handful of studies have examined decisionmaking directly, with most of this research focusing on adult males. ${ }^{17} 18$ Male patients typically have the well-established and highly successful option of sperm banking available to them, whereas women's options are more invasive, more experimental, less effective, and may require significant delays in cancer treatment. The aim of the study was to examine how those diagnosed with breast cancer decide whether or not to pursue fertility preservation prior to beginning cancer treatment by drawing on interviews with women diagnosed prior to 40 years of age. Table 1 gives an overview of the fertility preservation options currently available to those with breast cancer. Understanding the needs and concerns of women with cancer as they contemplate fertility preservation is vital for health care practitioners in order to best help patients make decisions that will allow them reach their fertility and family goals.

\section{METHODS}

\section{Data and sample}

Data come from an Institutional Review Board (IRB)-approved interview-based study on cancer and fertility with 71 women from the USA who were diagnosed with breast cancer prior to 40 years of age with most diagnosed within the past 3 years (Table 2). Interviews were conducted during 2008 and 2009. The sample was recruited through advertisements in e-newsletters and message boards aimed at those with breast cancer. Respondents had a range of diagnoses, breast cancer types and stages of the disease. The resulting sample is not representative of those with a history of breast cancer. Rather, a purposive sample was chosen for whom cancer-related infertility could potentially be an issue by choosing an age range (under 40 years) and cancer type 2022 that puts women at risk. This article examines a subsample of 34 respondents - all respondents from the study who discussed fertility preservation options with their physicians and who decided whether or not to pursue fertility preservation prior to beginning cancer treatment. Elsewhere, we discuss the overall sample $(n=71)$ and the factors that influenced whether or not fertility preservation was discussed prior to treatment. $^{23}$ (All names are pseudonyms.)

Semi-structured phone interviews averaged 60 minutes and respondents were read an IRB-approved statement of informed consent before agreeing to participate. Interview topics included diagnostic experiences, fertility concerns and experiences, treatment decisions and family plans. With all 71 respondents interviewers used a core interview guide, which 
Table 2 Sample demographics for the study participants $(n=34)$

\begin{tabular}{|c|c|c|c|}
\hline Demographic & Overall & $\begin{array}{l}\text { Fertility preservation=No } \\
(n=19,56 \%)\end{array}$ & $\begin{array}{l}\text { Fertility preservation=Yes } \\
(n=15,44 \%)\end{array}$ \\
\hline \multicolumn{4}{|l|}{ Race/ethnicity } \\
\hline Caucasian, non-Hispanic & $76.5 \%$ & $78.9 \%$ & $73.3 \%$ \\
\hline African-American & $20.6 \%$ & $15.8 \%$ & $26.7 \%$ \\
\hline Asian & $2.9 \%$ & $5.3 \%$ & $0.0 \%$ \\
\hline Have a Bachelor's Degree or higher & $97.1 \%$ & $94.7 \%$ & $100.0 \%$ \\
\hline Married/partnered & $64.7 \%$ & $73.7 \%$ & $53.3 \%$ \\
\hline Engaged & $8.8 \%$ & $15.8 \%$ & $0.0 \%$ \\
\hline With children & $23.5 \%$ * & $31.6 \%$ * & $13.3 \%$ \\
\hline Mean age at time of interview (years) & 34.1 & 34.6 & 35.5 \\
\hline Mean age at time of first diagnosis (years) & 32.1 & 32.2 & 32.0 \\
\hline Less than 3 years since most recent diagnosis & $88.2 \%$ & 78.9 & $100.0 \%$ \\
\hline Have health insurance & $100.0 \%$ & $100.0 \%$ & $100.0 \%$ \\
\hline
\end{tabular}

${ }^{\star}$ One respondent has a stepchild. All other children are biological.

remained flexible to capture respondents' varied experiences. For example, the sub-sample of 34 was asked about their fertility preservation decisions whereas the other participants were not because they had not discussed fertility preservation with their physicians.

\section{Coding and analysis}

We did not go into the data to test specific hypotheses because we wanted to reflect the self-described experiences of the women, and the themes described below emerged from an inductive analysis. Interviews were fully transcribed and the coding schema occurred in three stages. First, we categorised which fertility preservation treatment options respondents contemplated. Second, we identified factors that shaped their decision. During their interviews, respondents were asked directly whether or not they went ahead with fertility preservation and how they arrived at their decision. Finally, we took the aforementioned individual considerations and developed a set of common themes. As the coding progressed, it became clear that three sets of factors were significant in influencing respondents' decision-making: perceived benefits, inhibiting concerns and influential relationships.

\section{RESULTS}

Influential factors: facilitating and inhibiting

As outlined in Table 3, 44\% of the sample went ahead with fertility preservation, with most choosing egg/ embryo banking. Within our sample, whether or not to harvest oocytes for egg/embryo banking was the main fertility preservation decision respondents felt they needed to make with other options being secondary. Moreover, we found three sets of common issues that shaped respondents' fertility preservation decisions: (1) perceived benefits, (2) inhibiting concerns and (3) influential relationships.

\section{Perceived benefits}

An insurance policy

Many respondents spoke of pursuing fertility preservation in terms of wanting added "insurance". Enette, aged 28 years and newly diagnosed, had a "slight" risk according to her doctors of going into ovarian failure post-chemotherapy. Enette and her husband very much want children, so her decision to delay chemotherapy in order to bank embryos was a way she could help ensure that they would be able to reach their family goals:

"Well, the benefit was that it was an insurance policy, basically, should I ever - you know because they basically said if you go into ovarian failure, there's no going back. There's absolutely nothing we can do. So we looked at it as we may never need these but if we do, then they're there."

Many respondents were also not convinced that their fertility would be compromised and their banked embryos/oocytes were seen as a backup plan. This added insurance gave some respondents a sense

Table 3 Fertility preservation options contemplated and completed by respondents $(n=34)$

\begin{tabular}{|c|c|c|}
\hline $\begin{array}{l}\text { Fertility } \\
\text { preservation } \\
\text { option }\end{array}$ & $\begin{array}{l}\text { Fertility } \\
\text { preservation option } \\
\text { contemplated }\end{array}$ & $\begin{array}{l}\text { Fertility preservation } \\
\text { option completed } \\
44 \%(n=15)\end{array}$ \\
\hline Embryo banking & $34^{*}$ & 7 \\
\hline Egg banking & & 5 \\
\hline $\begin{array}{l}\text { Ovarian } \\
\text { suppression }\end{array}$ & 6 & 5 \\
\hline $\begin{array}{l}\text { Ovarian tissue } \\
\text { cryopreservation }\end{array}$ & 5 & 1 \\
\hline Multiple options & - & 3 \\
\hline
\end{tabular}


of control over their futures and their cancer. Tamara, a 36-year-old married respondent with no children, discussed how undergoing emergency in vitro fertilisation (IVF) allowed her to feel in charge of her cancer:

"The benefits, I mean are huge for I think - for people's ability to have their own child if that's important to them, to feel empowered that they're controlling the situation and also to protect them from feeling a loss of their fertility."

\section{"Healthier" eggs}

Several respondents discussed how freezing eggs/ embryos would allow them to use "younger" and "healthier" eggs when they tried to conceive in the future. Allison, a 27-year-old married mother of one, was told she had a 50/50 chance of her fertility being impacted by her treatment. What further upset Allison was that she was advised to wait 5 years before trying to conceive due to taking Tamoxifen. Allison banked embryos because it would give her the option to use her own younger, "healthier" eggs in the future:

"They would be my 27-year-old eggs and not my [older] eggs. ... So it would be a healthier egg. Probably have less problems than the ones - you get older, your baby could develop more problems and issues."

\section{Inhibiting concerns}

\section{Financial costs}

Respondents also weighed many concerns against the perceived benefits as they made their fertility preservation decisions. Fertility preservation and egg/ embryo storage can be expensive and are not routinely covered by insurance in the USA. For a few, the absolute cost at the time of their diagnosis was the determining factor dissuading them from pursuing fertility preservation. Jenna, a 32-year-old single mother, felt her decision to opt-out of fertility preservation was a financial one:

"I mean I had the bills from treatment piling up and I just - I couldn't even consider coming up with the money I needed to freeze eggs."

Cost factored into the decision-making process in another way: many respondents were concerned about spending money for a procedure they might not need as the impact of treatment on their fertility was unknown. Although Enette did bank embryos, she thought extensively about the costs for something she might not ultimately use:

"The risk was that insurance doesn't cover it and it's extremely expensive and it could be a really expensive thing that you never use."

\section{Fertility history}

Several respondents had a history of infertility prior to their cancer diagnosis and these experiences often deterred respondents from pursuing fertility preservation. Jackie, a 31-year-old engaged respondent, had a history of hormonal issues and had already been told by a doctor that she would have a hard time ever conceiving. The expense of storing embryos concerned her, but Jackie opted not to pursue embryo banking because she had already become used to the idea of not having biological children:

"... I pretty much figured I couldn't have kids even before I was diagnosed with cancer. So I didn't have any kind of big - I didn't have that shock that I had breast cancer and I wouldn't be able to have kids. I knew before I had breast cancer I probably wouldn't be able to have kids."

\section{Overwhelmed}

Some respondents described an intense emotional experience of having to make fertility preservation decisions while grappling with a potentially lifethreatening illness. Decisions have to be made quickly due to impending cancer treatment. For some, the decision itself became too overpowering. Aimee, a 32-year-old newlywed, described being too overwhelmed with her cancer diagnosis and personal life to make the decision to go ahead with emergency IVF:

"Maybe because of the time frame. It happened in like a week so that kind of limited what options I was given. And also maybe because I felt like I was going through so much. On top of dealing with my cancer diagnosis, I was getting married because we had moved everything up. It just was too much to deal with..."

Health-related concerns

Fertility preservation decisions are embedded in a cluster of interrelated decisions that cancer patients face before treatment begins, and respondents were almost universally concerned about the impact that harvesting eggs/embryos could have on their cancer and treatment plans. Jocelyn, a 39-year-old married stepmother, decided not to bank embryos despite wanting to have a biological child with her husband. Like most of the other respondents whose breast cancer was hormonally based, Jocelyn did not want to risk taking the additional hormones required for banking eggs/embryos:

"I knew the risks, if I was able to have my eggs harvested ... I would have to pump my body up with hormones which could make the cancer, if there was any cancer in my body, could make it more stimulated because I was estrogen-positive."

Jocelyn was also concerned about delaying chemotherapy for hormonal injections and oocyte harvesting, which can take weeks:

"I felt like I didn't have a lot of time to waste, that I needed to be able to start my [chemo] treatments. 
Because in my mind I wanted, if there was any cancer still in my body, I wanted to kill it before it grew any more."

\section{Success rates}

Although embryo banking is considered to be the standard option for women who want to pursue fertility preservation, it by no means guarantees a future live birth, and most other options are still considered experimental, including egg banking. Respondents were concerned with the success rates of the various procedures - particularly in light of the fact that their fertility might not ultimately be compromised. Aimee, who decided against banking embryos, was not convinced that emergency IVF would help her become pregnant in the future:

"So doing a cost-benefit analysis, if you only have one egg the likelihood of that egg, once I'm well and the likelihood of them being able to implant the egg and that being a child is - I mean it's not super high, there's just one."

\section{Influential relationships}

Physicians: influential guidance

Respondents also looked to important relationships in their lives as they made their decisions. Physicians, especially oncologists, played a key role in respondents' decision-making. For respondents, doctors were their main information source. Julia, a 32-year-old married mother of one, decided not to bank embryos because it would have delayed the treatment for her fast-growing tumour, and her oncologist felt it may not be necessary:

"From the feedback that we had got from the doctor that he had had patients recover completely from chemotherapy; we decided that we would just chance our ability to conceive later."

Many of those who did not carry out fertility preservation cited their physicians' opinion as an influential consideration.

Family relationships

In our sample, having prior children influenced whether or not a respondent pursued fertility preservation $-31.6 \%$ of those who decided against fertility preservation were already parents versus $13.3 \%$ of those who did (Table 2). Being a parent already dissuaded some from doing IVF as with Jessica, a married mother of one:

\footnotetext{
"It was just too much. I didn't want to delay chemo. I mean I didn't want to take hormone shots and do the harvesting. The whole thing would have delayed chemo. And I didn't - maybe if I had zero children, I might have been willing. But at one child, I'm not willing to do IVF."
}

Partners also influenced respondents' decisions. Those with partners/spouses considered their partners' parenting desires as they made their decision, as in the case of Julia (discussed above) who described both herself and her husband ("we") as making the decision not to freeze embryos. Other women saw themselves as being the primary decision-maker and looked to their partners to support their decision. Allison, a 28-year-old married mother of one, decided to delay treatment to do emergency IVF:

\section{"It was mainly me. I mean my husband was behind me $100 \%$, and he told me whatever I wanted to do, he was comfortable with. But, again, it was just piece of mind, getting that finished and knowing that they would be there after all that is finished."}

Being single also shaped these decisions. Since embryo freezing requires sperm, those without partners found this option unappealing although it has a much higher success rate compared to egg freezing alone. For Kari-Ann, aged 33 years, being single heavily influenced her decision:

"We went through several options and we came down to egg freezing, seeing as I was single and didn't have a partner. I didn't really want to use a sperm donor... For me, it wasn't even really a consideration to do embryo freezing because I just didn't like the idea of an unknown sperm donor. So it was pretty clear cut in terms of what to do."

Relationships with other family members were influential as well. In the absence of a partner, respondents most often described talking to their parents about their options. At times, parents even put pressure on their children because of their own desire for grandchildren. ${ }^{23}$ For Idelle, who is 39 years old and single, her parents played a direct role in her decision to do egg harvesting:

"Dad said, 'Here's the credit card, go get it. I want to make sure I'll have insurance on a grandchild."

\section{DISCUSSION}

\section{Main findings of the study}

Our study hoped to shed light on how women with breast cancer make fertility preservation decisions. Respondents' cancer and fertility prognoses, family goals, and decisions varied widely. However, we found common issues influencing their decisionmaking, including factors that encouraged fertility preservation (e.g. wanting a backup plan) and concerns that dissuaded respondents (e.g. history of infertility). Respondents' decisions were also made in the context of key relationships with physicians (most notably oncologists), spouses/partners and parents.

\section{Study strengths and limitations}

Through interviews, respondents were able to share their experiences of making fertility preservation decisions. However, this study had several limitations. Respondents were highly educated, most were 
professionals, and all had health insurance. A more diverse sample could reveal greater financial barriers, which were not the deciding factor for most of our respondents. Also, respondents rarely objected to the use of reproductive technologies. Including greater socioeconomic, cultural and religious diversity may show more varied views of reproductive technologies and how they could shape fertility preservation decisions. ${ }^{5}$ Interviews occurred retrospectively - a common limitation in research on cancer and fertility concerns (for discussion see Peate et al. ${ }^{9}$ ). Interviews at the time of diagnosis would provide more insight into the factors that drive fertility preservation decision-making.

\section{Comparison with the literature}

Our findings extend research on how fertility preservation decisions are made. Schover et al. ${ }^{18}$ found that a stronger desire for children was related to whether men banked sperm. However, from their prospective study of fertility preservation decisions among newly diagnosed breast cancer patients aged under 40 years, Peate et $a l^{5}$ concluded that a more "definite desire" (p. 1676) for children was not related to whether or not respondents considered emergency IVF. We also did not find a stronger absolute preference for children among those who opted for fertility preservation, suggesting that motivations for fertility preservation may differ by gender. From their study of cancer survivors' experiences with fertility preservation in the UK, Wilkes et al. ${ }^{24}$ proposed that men's interest in fertility preservation may be more influenced by their immediate desire for children. Our findings along with Peate ${ }^{5}$ suggest that women may think more about long-term parenting goals and not just immediate parenting plans.

Wilkes et al.' ${ }^{24}$ sample included male and female cancer survivors and suggested that fertility preservation decisions for men can be more straightforward. The adult male survivors in their study recalled sperm banking being a seamless part of their cancer care. Though not all men with cancer report such positive experiences, ${ }^{13}$ research on female cancer patients and survivors, ${ }^{5} 1424$ including our own study, show women's fertility preservation decisions are typically more difficult because they face options that are more invasive, experimental and that can significantly delay cancer treatment.

A common conclusion throughout research on fertility preservation is that those with cancer want as much detailed information regarding fertility risks and potential solutions as possible, ${ }^{5} 13$ which our findings support. Peate et al. ${ }^{5}$ found that their sample of newly diagnosed women had fairly low levels of fertility preservation knowledge and that decreased knowledge was associated with higher levels of decisional conflict. Respondents' experiences support this assertion as many struggled with understanding how egg retrieval may impact their cancer, success rates, their likely fertility risk, and so forth. The more informed respondents were the less "overwhelmed" they described themselves as being as they made their final decision.

Our respondents may be more knowledgeable than other studies on fertility preservation, which often include respondents who did not discuss fertility issues with their physicians, unlike our sample. However, there were still important gaps in our sample's understanding of fertility preservation. Respondents defined fertility preservation as the choice of whether or not to harvest oocytes for egg/ embryo banking almost exclusively with other options being very much secondary. Recent best practice guidelines for fertility preservation advocate that a range of options be discussed including traditional options (e.g. embryo banking), investigational techniques (e.g. ovarian tissue cryopreservation) and even alternatives to biological parenthood (e.g. adoption), ${ }^{671920}$ but respondents rarely, if ever, described discussing such varied options with their physicians.

Lastly, researchers have concluded that those with cancer prefer to learn about fertility preservation from physicians ${ }^{9} 11$ and consider physicians to be their main information source for fertility preservation. $^{5} 25$ Our respondents' experiences affirm this, with most respondents turning to physicians for information and family members for emotional support.

\section{Implications for the future}

Fertility preservation decision-making also needs to be studied for other cancers, which may have different fertility risks, advisable options and overall survival rates and, therefore, different considerations as patients make fertility-related decisions. Moreover, our study suggests that women facing cancer should be informed of all of their options and not just egg/embryo banking since other options may be a better fit for a patient's prognosis and goals. Respondents made decisions weighing health and financial benefits and costs in light of their prognosis, but also brought in other factors, including familial relationships, fertility history and life-stage issues (also see Wilkes et $a ._{.}{ }^{24}$ ), and health care practitioners should be aware of what weighs on a patient's decision. Respondents also felt that formalised support services did not meet the unique needs of younger women with breast cancer particularly with regard to fertility. ${ }^{23} 25$ Opportunities for those who are pretreatment to connect with others who have been through, or are also dealing with, fertility preservation decisions for support would be useful. Respondents will also continue to deal with fertility concerns and additional decisions post-cancer. Resources that allow cancer survivors to find up-to-date information regarding reproductive technologies, post-cancer fertility issues, and continued peer support would undoubtedly be beneficial. 


\section{CONCLUSIONS}

Fertility can be a major source of distress for cancer survivors, ${ }^{1-5}$ but not all who are eligible are taking advantage of fertility preservation. One study of younger adult women with breast cancer found only $10 \%$ underwent fertility preservation. ${ }^{22}$ Though systemic barriers exist to more patients choosing fertility preservation, including availability of facilities, coverage for such procedures, and physician's knowledge of the issue, ${ }^{62627}$ understanding the needs and concerns of women facing cancer can encourage health care providers to help patients make informed decisions and lessen the potential for fertility-related stress and problems further down the line.

Funding This research was supported by the Oncofertility Consortium NIH 8UL1DE019587, 5RL1HD058296.

\section{Competing interests None.}

Ethics approval This study was approved by Northwestern University's Institutional Review Board (IRB).

Provenance and peer review Commissioned; externally peer reviewed.

\section{REFERENCES}

1 Wenzel L, Dogen-Ates A, Habbal R, et al. Psychosocial, ethical, and legal issues defining and measuring reproductive concerns of female cancer survivors. J Natl Cancer Inst Monogr 2005;34:94-98.

2 Rosen A, Rodriguez-Wallberg KA, Rosenzweig L. Psychosocial distress in young cancer survivors. Semin Oncol Nurs 2009;25:268-277.

3 Dunn J, Steginga SK. Young women's experience of breast cancer: defining young and identifying concerns. Psychooncology 2000;9:137-146.

4 Lee SJ, Schover LR, Partridge AH, et al. American Society of Clinical Oncology recommendations of fertility preservation in cancer patients. J Clin Oncol 2006;24:2917-2931.

5 Peate M, Meiser B, Friedlander M, et al. It's now or never: fertility-related knowledge, decision-making preferences, and treatment intentions in young women with breast cancer - An Australian fertility decision aid collaborative study. J Clin Oncol 2011;29:1670-1676.

6 Snyder KA, Pearse W. Discussing fertility preservation options with patients with cancer. JAMA 2011;306:202-203.

7 Canada AL, Schover LR. Research promoting better patient education on reproductive health after cancer. J Natl Cancer Inst Monogr 2005;34:98-100.

8 Partridge AH, Gelber S, Peppercorn J, et al. Web-based survey of fertility issues in young women with breast cancer. J Clin Oncol 2004;22:4174-4183.

9 Peate M, Meiser B, Hickey M, et al. The fertility-related concerns, needs and preferences of younger women with breast cancer: a systematic review. Breast Cancer Res Treat $2009 ; 16: 215-223$.
10 Snyder KA. Oncofertility and the social sciences. Cancer Treat Res 2007;138:137-148.

11 Thewes B, Meiser B, Taylor A, et al. Fertility- and menopauserelated information needs of younger women with a diagnosis of early breast cancer. J Clin Oncol 2005;23:5155-5165.

12 Duffy CM, Allen SM, Clark MA. Discussions regarding reproductive health for young women with breast cancer undergoing chemotherapy. J Clin Oncol 2005;23:766-773.

13 Chapple A, Salinas M, Ziebland S, et al. Fertility issues: the perceptions and experience of young men recently diagnosed and treated for cancer. J Adolesc Health 2007;40:69-75.

14 Quinn GP, Vadaparampil ST, Jacobsen PB, et al. Frozen hope: fertility preservation for women with cancer. J Midwifery Womens Health 2010;55:175-180.

15 Jukkala A. Breast cancer survivors and fertility preservation: ethical and religious considerations. Semin Oncol Nurs 2009;25:278-283

16 Rosoff PM, Katsur ML. Preserving fertility in young cancer patients: a medical, ethical and legal challenge. J Philos Sci Law 2003;3. http://www6.miami.edu/ethics/jpsl/archives/papers/ preservingFert.html [accessed 14 November 2011].

17 Achille MA, Rosberger Z, Robitaille R, et al. Facilitators and obstacles to sperm banking in young men receiving gonadotoxic chemotherapy for cancer: the perspective of survivors and health care professionals. Hum Reprod 2006;21:3206-3216.

18 Schover LR, Brey K, Lichtin A, et al. Knowledge and experience regarding cancer, infertility, and sperm banking in younger male survivors. J Clin Oncol 2002;20:1880-1889.

19 Fertile Hope. "Female reproductive options". 2007. http:// www.fertilehope.org/healthcare-professionals/clinical-tools/ female_options_v3.pdf [accessed 14 November 2011].

20 Jeruss JS, Woodruff TK. Preservation of fertility in patients with cancer. N Engl J Med 2009;360:902-911.

21 Ernst E, Bergholdt S, Jørgensen JS, et al. The first woman to give birth to two children following transplantation of frozen/ thawed ovarian tissue. Hum Reprod 2010;25:1280-1281.

22 Partridge AH, Gelber S, Peppercorn J, et al. Fertility and menopausal outcomes in young breast cancer survivors. Clin Breast Cancer 2008;8:65-69.

23 Snyder KA, Pearse W. Crisis, social support, and the family response: exploring the narratives of young breast cancer survivors. J Psychosoc Oncol 2010;28:413-431.

24 Wilkes S, Coulson S, Crosland A, et al. Experience of fertility preservation among younger people diagnosed with cancer. Hum Fertil 2010;13:151-158.

25 Gorman JR, Usita PM, Madlensky L, et al. Young breast cancer survivors: their perspectives on treatment decisions and fertility concerns. Cancer Nurs 2011;34:32-40.

26 Quinn GP, Vadaparampil ST, Gwede CK, et al. Discussion of fertility preservation with newly diagnosed patients: oncologists' views. J Cancer Surviv 2007;1:146-155.

27 Quinn GP, Vadaparampil ST, King L, et al. Impact of physicians' personal discomfort and patient prognosis on discussion of fertility preservation with young cancer patients. Patient Educ Couns 2009;77:338-343. 